\title{
Everolimus as an mTOR Inhibitor Suppresses Endometriotic Implants: an Experimental Rat Study
}

\author{
Der mTOR-Inhibitor Everolimus verringert endometriotische \\ Krankheitsherde: Eine experimentelle Studie an der Ratte
}

Authors

T. Kacan ${ }^{1}$, C. Yildiz², S. Baloglu Kacan ${ }^{3}$, M. Seker ${ }^{1}$, H. Ozer ${ }^{4}$, A. Cetin ${ }^{2}$

Affiliations

1 Department of Medical Oncology, Cumhuriyet University School of Medicine, Sivas, Turkey

2 Department of Obstetrics and Gynecology, Cumhuriyet University School of Medicine, Sivas, Turkey

3 Department of Internal Medicine, Sivas Numune Hospital, Sivas, Turkey

4 Department of Pathology, Cumhuriyet University School of Medicine, Sivas, Turkey

Key words

apoptosis, endometriosis, everolimus, ovarian reserve

Schlüsselwörter

Apoptose, Endometriose, Everolimus, ovarielle Reserve

received 9.6.2016

revised 28.7.2016

accepted $\quad 17.8 .2016$

Bibliography

DOI http://dx.doi.org/10.1055/s-0042-115566

Geburtsh Frauenheilk 2017; 77: 66-72 @ Georg Thieme Verlag KG

Stuttgart · New York I ISSN 0016-5751

Correspondence

Turgut Kacan, MD

Department of Medical Oncology, Cumhuriyet University

School of Medicine

Kampus, 58100 Sivas, Turkey

kacanturgut@gmail.com

\section{ABSTRACT}

Introduction Mammalian target of rapamycin is a pathway to block apoptosis. Recent studies showed that the activity of mammalian target of rapamycin pathway increases in endometriotic lesions. Aim of the present study was to study the effect of everolimus agent, a rapamycin analog, in an experimental endometriosis model.

Materials and Methods Endometriosis established by the autotransplantation of uterine tissue in the peritoneal cavity was confirmed in 24 rats. The animals were then randomly divided into three groups to receive either everolimus $(1.5 \mathrm{mg} / \mathrm{kg} /$ day, p.o.), anastrozole $(0.004 \mathrm{mg} /$ day, p. o.), or normal saline $(0.1 \mathrm{~mL}$, i. p.) for 14 days. Endometriotic foci were excised, stained with hematoxylin and eosin, and endometriosis was scored semiquantitatively. In addition, immunohistochemical examination were performed using primary antibodies of vascular endothelial growth factor, CD117, and Bax.

Results Both anastrozole and everolimus lowered endometriosis scores. Significant decreases in ovarian follicles were observed following anastrozole treatment but not everolimus treatment.

Conclusion Through its apoptosis-promoting effect, everolimus suppressed endometriotic foci without negatively affecting ovarian reserve. These findings support the hypothesis that everolimus merits further study on the way to developing a new endometriosis drug.

\section{ZUSAMMENFASSUNC}

Einleitung Mammalian Target of Rapamycin (mTOR, deutsch: Ziel des Rapamycins im Säugetier) funktioniert als Signalweg zur Verhinderung von Apoptose. Neue Studien haben gezeigt, dass die Aktivität des mTOR-Signalwegs in endometriotischen Läsionen erhöht ist. Ziel dieser Studie war es, die Auswirkungen von Everolimus, einem Rapamycin-Analogon, in einem experimentellen Endometriosemodell zu studieren.

Material und Methoden Es wurde eine Endometriose durch Autotransplantation von Gebärmuttergewebe in die Bauchhöhle von 24 Ratten hervorgerufen. Das Vorhandensein der Endometriose wurde anschließend überprüft. Die Tiere wurden danach in 3 Gruppen randomisiert und erhielten über 14 Tage hinweg entweder Everolimus (1,5 mg/kg/d, p. o.), Anastrozol (0,004 mg/d, p. o.), oder Kochsalzlösung $(0,1 \mathrm{~mL}$, i. p.). Endometriotische Krankheitsherde wurden operativ entfernt, mit Hämatoxylin und Eosin eingefärbt, und das Ausmaß der Endometriose wurde semiquantitativ bewertet. Zusätzlich wurde eine immunhistochemische Analyse mit Primärantikörper von Vascular Endothelial Growth Factor, CD117 und Bax durchgeführt.

Ergebnisse Die Gabe von Anastrozol wie auch von Everolimus verringerte die Endometriosewerte. Nach der Behandlung mit Anastrozol wurde aber ein signifikanter Rückgang ovarieller Follikel vermerkt, der nach einer Behandlung mit Everolimus nicht auftrat.

Schlussfolgerung Die Apoptose-fördernde Wirkung von Everolimus verringerte die endometriotischen Krankheitsherde, ohne dass die ovarielle Reserve negativ beeinflusst wurde. Dieses Ergebnis stützt die Vermutung, dass weitere Studien zur Wirksamkeit von Everolimus als potenzielles Medikament gegen Endometriose nötig sind. 


\section{Introduction}

Endometriosis is an estrogen-dependent chronic inflammatory disease defined by the presence of endometrial glands and stroma outside the uterine cavity, but in pelvic, peritoneal and rectovaginal septum. It can cause dysmenorrhea, chronic pelvic pain, irregular uterine bleeding and infertility [1]. Although its prevalence is not exactly known, it is thought to affect about 176 million women of reproductive age worldwide [2]. The average annual total cost per woman was $€ 9579$ and the annual societal burden of endometriosis-associated symptoms can be extrapolated to $€ 49.6$ billion in the USA [3].

Because of the nature of endometriosis as an estrogen-dependent disease, the basic aim of modern hormonal treatments is to establish a postmenopausal environment. Gonadotropin hormone analogs, androgens, aromatase inhibitors and danazol are used for short-term treatments, while oral contraceptives and progestins are used for long-term suppression of the condition [4]. Vascular endothelial growth factor (VEGF) family is one of the major elements of angiogenesis process that plays a significant role in the development of endometriotic foci. It has been shown that VEGF inhibitors could be effective in the treatment of endometriosis [5].

Despite the lack of a theory that can fully explain the development of endometriosis yet, recent evidence points to the impairments of angiogenesis and apoptosis processes [6]. Although the abnormal expressions of apoptosis-related major protein Fas, Fas ligand, BCL2 and Baxin endometriosis patients have been shown to decrease programmed deaths of endometrial cells outside the uterine cavity, it is not exactly understood why the apoptosis process is suppressed [7]. Mammalian target of rapamycin (mTOR) pathway regulates the function of many proteins involved in proliferation and apoptosis via the mTOR/AKT pathway [8]. Eutopic endometrium tissue of women with endometriosis fundamentally differs from that of women without the condition. These differences include proliferation, adhesion molecules, immune components, steroids, cytokine productions, gene expression and protein synthesis $[9,10]$.

Mammalian target of rapamycin pathway was observed to be more active in endometriotic foci than in healthy endometrium tissue. Therefore, it has been suggested that mTOR inhibition in endometriosis foci could improve apoptosis process and be effective in the treatment of endometriosis [10]. Everolimus is a rapamycin analogue that selectively inhibits mTOR [11]. The aim of the present study was to investigate the effect of everolimus on an experimental endometriosis model in rats.

\section{Materials and Methods}

The study was carried out according to the guidelines of Cumhuriyet University for the Care and use of Laboratory Animals and approved by the Animal Research Ethics Committee of Cumhuriyet University (approval ID: 394). Adult female Wistar-Albino rats (220-240 g) (obtained from Animal Reproduction Centre of Cumhuriyet University [Sivas, Turkey]) were used in the present study.
Rats were fed on standard feed and water, maintained at a $22^{\circ} \mathrm{C}$ controlled environment under 12:12 hours light/dark cycles. Maximum effort was exerted to minimize the number of animals used and to decrease their suffering. The rats were weighed before and after the experiment, and no difference was found for mean weights of rats before and after the experiment.

Twenty eight rats were used in this study in order to induce endometriosis. Twenty four of them had endometriotic implants. One of them died due to the complications of anesthesia, one of them had peritoneal infection, and two of them had no endometriotic implants. These rats were excluded. Post hoc power analysis revealed that at least $80 \%$ of power was obtained.

\section{Induction of endometriosis}

Endometriosis was induced by uterine tissue autotransplantation into the peritoneal cavity using laparotomy method as described by Vernon and Wilson [12]. Ketamine $(60 \mathrm{mg} / \mathrm{kg}$ ) (Ketalar 1; Eczacibasi Warner-Lambert, Istanbul, Turkey) and xylazine $(7 \mathrm{mg} / \mathrm{kg})$ (Rompun 1, Bayer, Istanbul, Turkey) were administered intraperitoneally for aseptic conditions. The left uterine horn was excised, immediately immersed in physiological serum, opened longitudinally and a $5 \mathrm{~mm}$ by $5 \mathrm{~mm}$ piece was prepared. This endometrial tissue was placed to the anterior right abdominal wall via suturing near to a vascular area without removing the myometrium. Then the abdominal incision was closed. No other medication was administered and rats were observed for 21 days.

\section{Evaluation of the endometriotic tissue}

The rats were subjected to a second laparotomy to evaluate the presence of endometriosis. Twenty-four rats which had evident endometriotic implants were randomly divided into three experimental groups, i.e. everolimus ( $1.5 \mathrm{mg} / \mathrm{kg} /$ day, p. o.), anastrozole ( $0.004 \mathrm{mg} /$ day, p. o. $)$ or normal saline treatments $(0.1 \mathrm{ml}$, i. p.) for 14 days.

\section{Collection of tissue samples}

A third laparotomy was carried out to obtain endometriotic tissue samples and ovaries 21 days after the second laparotomy. After the procedure, the rats were sacrificed under pentobarbital sodium anesthesia. All surgical procedures were performed by the same author (Ç.Y.).

\section{Histopathological examinations}

Endometriotic implants and ovaries were stored in 10\% formalin solution. Histological examinations were performed using hematoxylin and eosin (H \& E) staining. For immunohistochemical (IHC) examinations, primary antibodies used were VEGF, CD117, and Bax. The same author who was blinded for the study drugs (H. O.) evaluated all histological and IHC examinations.

\section{Histological examination of endometriotic implants}

After $\mathrm{H} \& \mathrm{E}$ staining, semiquantitative histological classification of endometriosis was carried out according to Keenan et al. [13]. This classification was based on the preservation of the epithelial layer of the endometrium: well-preserved epithelial layer = score 3 , moderately preserved epithelium with leukocyte infiltra- 
tion = score 2, poorly-preserved epithelium (only some epithelial cells) = score 1 , no epithelium = score 0 .

\section{Immunohistochemical examination of endometriotic implants}

Endometriotic implants were immunohistochemically stained using BenchMark XT (Ventana Medical Systems, Roche) system. The primary antibodies against VEGF (Ab-4, Clone BFD31, Lab Vision, USA), CD117 (K69, Lab Vision, USA), and Bax (Ab-2, Clone 5B7, LabVision, USA) were used. VEGF staining was evaluated according to Donnez et al. [14]. VEGF histological scores $(H)$ were calculated using formula $\mathrm{H}=\Sigma \mathrm{Pi}$, where $\mathrm{H}$ is the intensity ranging between 0 (negative cells) and 3 (intensely stained cells), and $P$ is the percentage of stained cells for each given i, with p-values of 1 (<15\%), 2 (15-50\%), 3 (50-85\%), 4 (>85\%) and 5 (staining $100 \%$ positive). CD117 and Bax was analyzed using an immunoreactive score (IRS) calculated by multiplication of the intensity $(0-3)$ by the percentage of stained cells $(0-4)$ [15]. Staining was scored for statistical analysis as follows: 0 points = negative, $1-4$ points = weak, and $6,8,9$ or 12 points $=$ strong.

\section{Histological examination of ovaries}

Both ovaries of rats were excised and fixed in $10 \%$ formalin, dehydrated with different ethanol solutions, cleared in xylene and embedded in paraffin. Six mm thick ovarian sections were taken and stained with $\mathrm{H} \& \mathrm{E}$. Five sections were taken from each ovary with a distance of at least $120 \mathrm{~mm}$ from each other to avoid counting the same follicles twice, and primordial, primary, secondary and antral follicles were determined in these sections.

\section{Statistical analyses}

All data were subjected to analysis of variance using SPSS version 20.0 for Windows (SPSS, Chicago, IL, USA). Tukey Post Hoc test was employed to determine the differences between groups for endometriosis score, ovarian follicle number, and staining scores of VEGF, CD117 and Bax. Results are shown as mean \pm standard error. $\mathrm{P}<0.05$ was considered significant.

\section{Results}

\section{Development of endometriosis, histological and immunohistochemical staining}

Experimental procedures were applied to rats in all groups without any evident side effects of drugs. Mean weights of rats were similar before and after the experiment. When the abdomens were examined via the second surgical procedure, it was observed that endometriotic implants developed vascularization, and cystic appearance was satisfactory. Histological evaluation confirmed the development of endometriotic tissues. Representative images of histological and immunohistochemical stainings (VEGF, CD117, Bax) of endometriotic lesions after normal saline, anastrozole and everolimus administering are given in $\mathbf{F}$ Figs. $\mathbf{1}$ and $\mathbf{2}$, respectively.
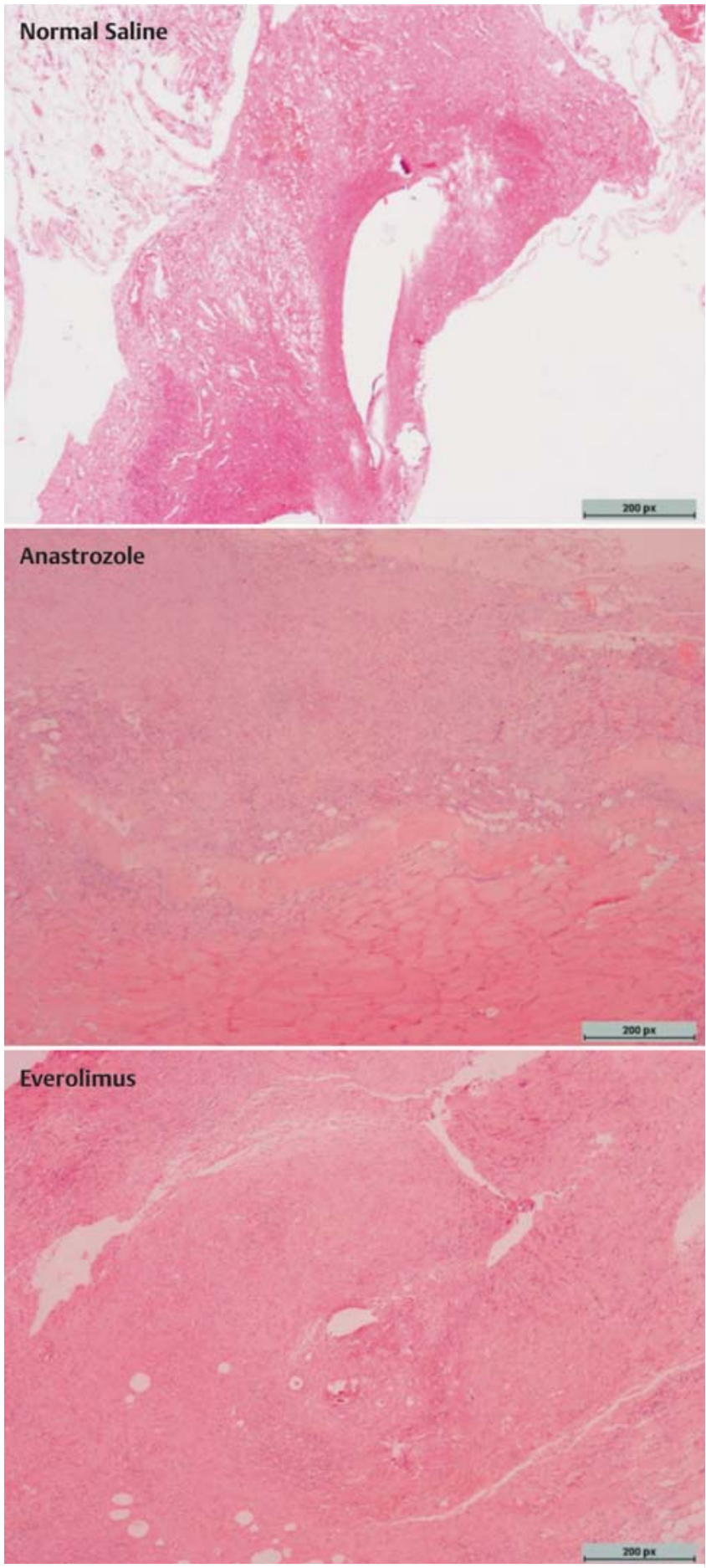

- Fig. 1 Representative histological images of endometriotic lesions in rats administered normal saline, anastrozole, and everolimus (H\&E × 40). Representative endometriotic tissues reveal poorly preserved epitelium in everolimus and anastrozole groups when compared to normal saline group. Scale bars, $200 \mathrm{px}$ in all images (1280 px in width). 


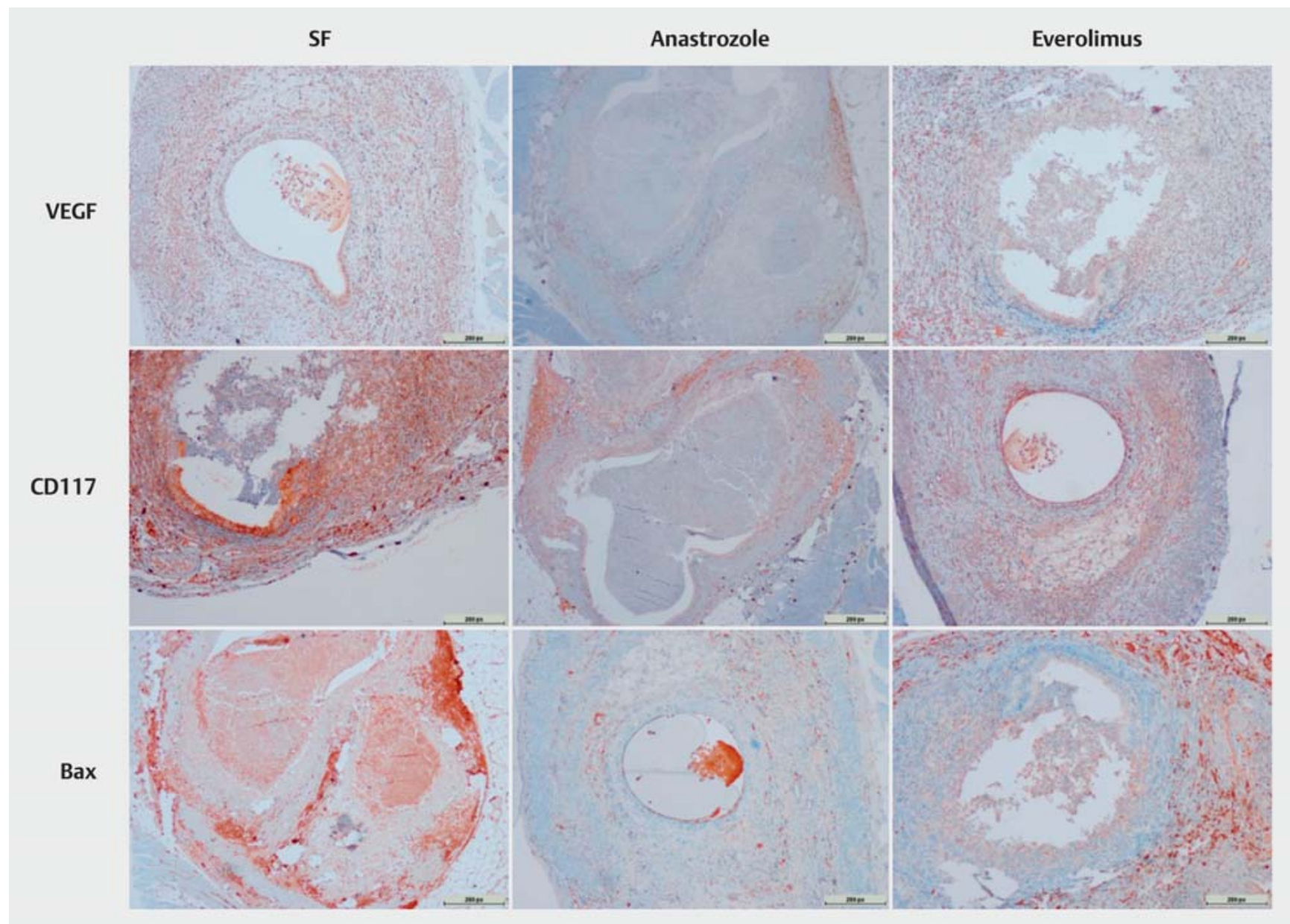

- Fig. 2 Representative immunohistochemical staining (VEGF, CD117, Bax) images of endometriotic lesions in rats administered normal saline, anastrozole, and everolimus. Scale bars, 200 px in all images (1280 px in width).

\section{Endometriosis score and ovarian follicle number}

The anastrozole and everolimus treatments significantly lowered the endometriosis scores compared to the normal saline administration $(\mathrm{p}<0.05)$ ( $\bullet$ Fig. 3 ). There was no significant difference between the anastrozole and everolimus groups regarding the endometriosis score $(p=0.459)$ ( $\bullet$ Fig. 3 ). Significant decreases were observed in the ovarian follicle number in the anastrozole group compared to the saline group $(p<0.05)$ ( $\triangleright$ Fig. 3 ). The ovarian follicle number in the everolimus group was significantly higher than in the saline group $(p<0.001)(\triangleright$ Fig. 3 ).

\section{Immunohistochemical staining score}

The anastrozole and everolimus treatments significantly lowered the VEGF staging score compared to the normal saline administration $(p<0.05)(\vee$ Fig. 4$)$, and no difference was found between the two study drugs $(p>0.05)$ ( $\vee$ Fig. 4).The CD117 staging scores (cell proliferation in endometriotic tissues) were significantly lower in the anastrozole and everolimus groups compared to that of the saline group $(p<0.001)(\triangleright$ Fig. 4$)$; however, no significant difference was found between the two drug groups $(p=0.632)(\triangleright$ Fig. 4). The Bax staging score was significantly low- er in the anastrozole treatment group compared to the saline and everolimus groups $(p<0.05)$ ( $\triangleright$ Fig. 4$)$. On the other hand, the everolimus and saline groups had similar Bax scores $(p=0.984)$ (॰ Fig. 4).

\section{Discussion}

Histological examination of endometriosis foci in an experimental rat endometriosis model revealed that the use of anastrozole and everolimus significantly lowered endometriosis development and suppressed the foci. Endometriosis scores in the anastrozole group were significantly lower than in the saline group, but did not differ from the everolimus treatment group. Immunostaining experiments using VEGF and CD117 showed that anastrozole and everolimus had similar effects on angiogenesis and cell division. Anastrozole treatment significantly lowered the apoptosis efficiency evaluated by Bax immunostaining compared to the saline group. Everolimus treatment led to only a slight, but not significant, decrease in apoptosis efficiency compared to the saline group. Histological examination of ovarian follicles showed that 

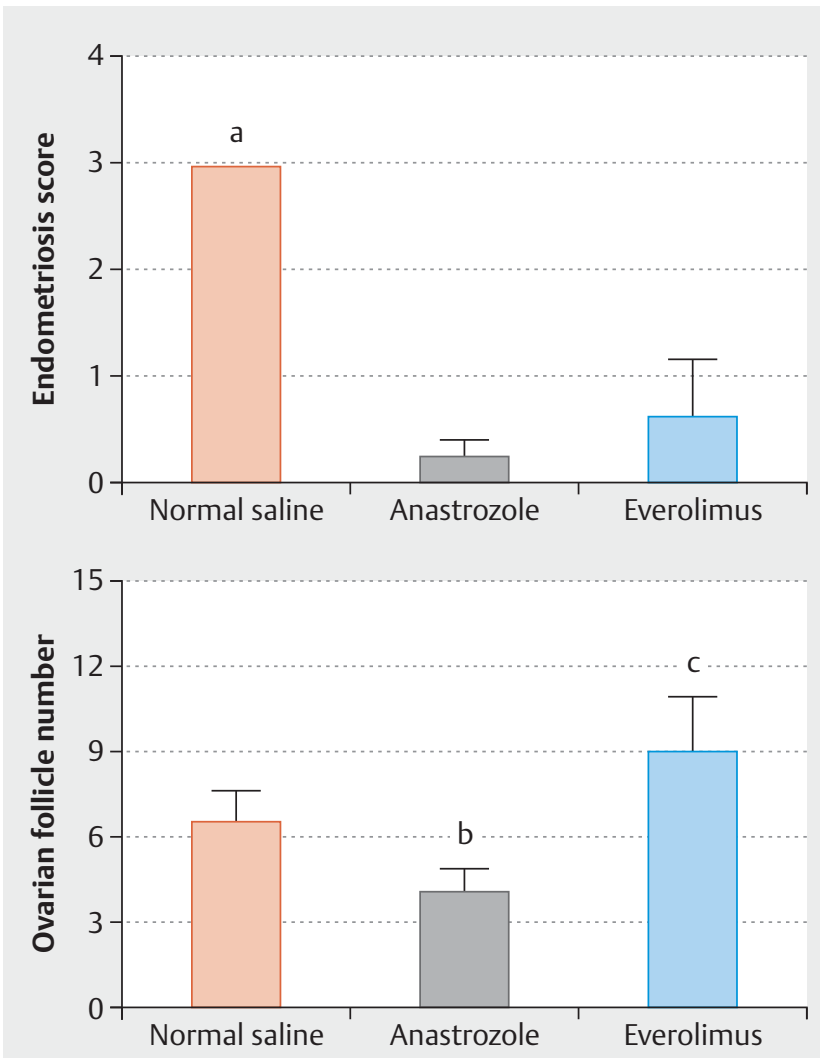

- Fig. 3 Endometriosis score and ovarian follicle number of normal saline, anastrazole, and everolimus groups. Data were expressed as mean \pm SEM (standard error of the mean). a $p<0.05$; normal saline vs. anastrazole and everolimus. b $\mathrm{p}<0.05$; anastrazole vs. normal saline and everolimus. с $p<0.05$; everolimus vs. normal saline.

anastrozole significantly lowered the ovarian follicle number whereas everolimus increased this number and this can be interpreted as a paradoxical finding. Although the increase of the ovarian follicle number implied that everolimus might not affect ovarian reserve, further studies are required in order to find the mechanism of ovarian follicle increase by everolimus. Since current treatments of endometriosis are mainly performed with hormonal drugs which can lead to a decrease in ovarian follicles [16], there is a need for new drugs with less effect on the ovarian follicles. Within this perspective, everolimus deserves to be examined more closely in the search for a new endometriosis drug.

Anastrozole is a third generation non-steroidal aromatase inhibitor. It decreases cell proliferation through inhibiting the transformation of androgens to estrogen in peripheral tissue [17]. Hormone suppression treatment has been shown to increase the apoptotic process in endometriotic foci. Anastrozole treatment was reported to decrease cell proliferation and to increase apoptosis [18]. There are other studies reporting that anastrozole did not increase apoptosis but decreased cell proliferation [19,20]. Similarly, we found that anastrozole did not enhance apoptosis but suppressed cell proliferation.

A common feature of modern endometriosis treatments is the suppression of ovarian hormonal functions in addition to lowering

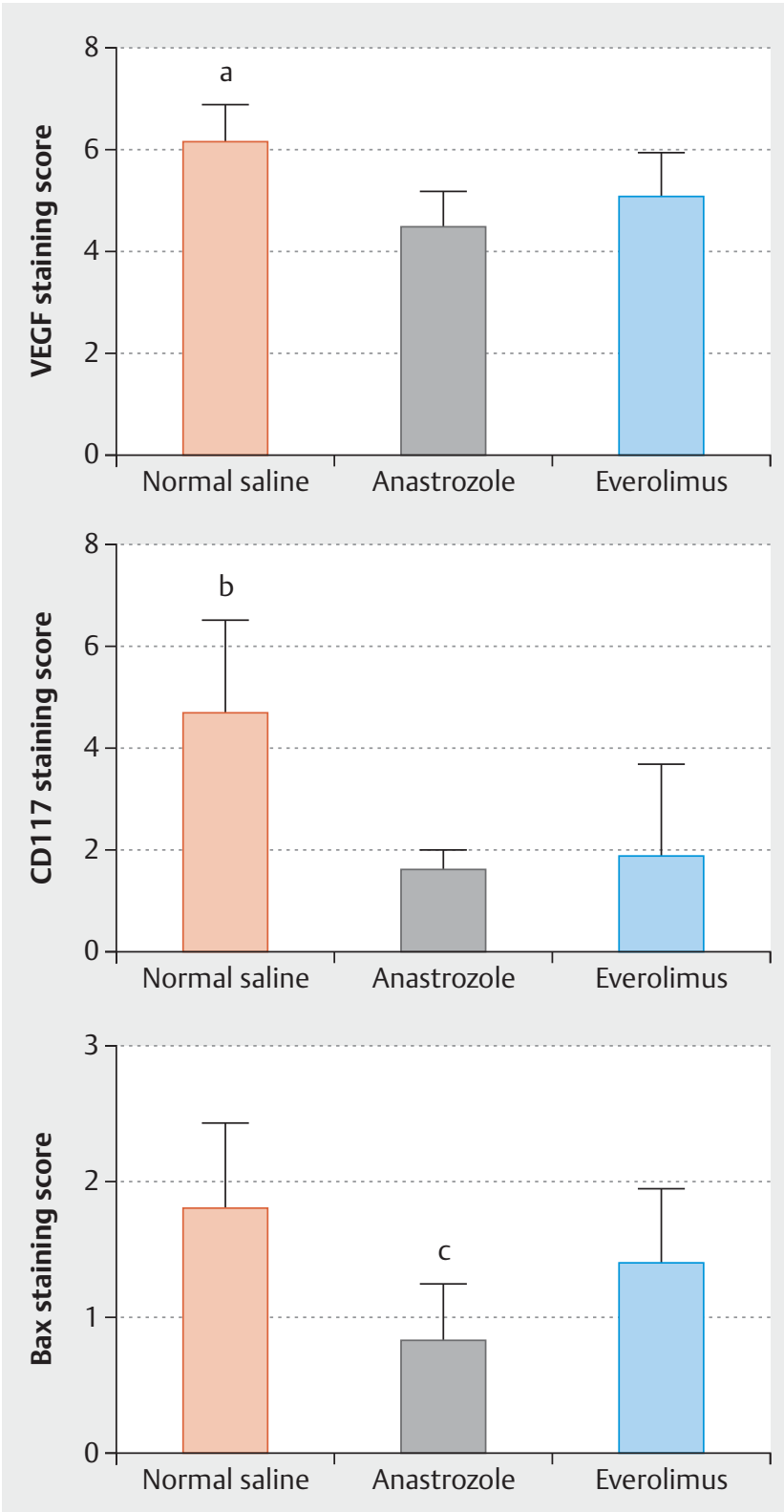

- Fig. 4 VEGF, CD117, and Bax staining scores of rats administered normal saline, anastrazole, and everolimus. Data were expressed as mean \pm SEM. a, b $p<0.05$; normal saline vs. anastrazole and everolimus. c $p<0.05$; anastrazole vs. normal saline and everolimus.

the peripheral estrogen production and efficiency [21]. Because of the side effects resulting from lowered estrogen levels, endometriosis treatment approaches aim to decrease side effects in the reproductive system originating from hormonal treatment using different agents such as dinitrosyl iron complexes [22], kisspeptin antagonists [23], statins [24], protease-activated receptor 2 antagonists [25] and antioxidants [26]. Although endometriosis is not a malign disease, angiogenesis, migration and apoptosis mechanisms are modified in endometriotic tissue [6, 27].

In the present preclinical study, we observed that everolimus, a rapamycin analogue which is an inhibitor of the mTOR pathway 
that plays a role in apoptosis and cell proliferation and has been shown effective in recent cancer treatment studies, had similar efficiency to that of anastrozole, an aromatase inhibitor, on endometriosis foci $[28,29]$. Studies investigating the effect of mTOR pathway on endometriosis pathogenesis showed elevated efficiency of mTOR which inhibited apoptosis in endometriotic foci and suggested mTOR inhibition as a potential endometriosis treatment. Nevertheless, there are not enough studies for such an approach yet [30,31].

Leconte et al. [10] showed that inhibition of mTOR-AKT pathway using temsirolimus resulted in suppression of deep endometriosis foci in both in vitro and in vivo conditions. They found that temsirolimus use $(3 \mathrm{mg} / \mathrm{kg}$ in $100 \mu \mathrm{L}$ PBS, 5 days per week for 2 weeks) led to significant decreases in endometriosis foci. In addition to lowering the apoptosis in endometriotic foci, the investigators revealed that the mTOR-AKT pathway also lowered oxidative stress and concluded that it could be effective in treatment of women with endometriosis. Studying the effect of progesterone and progestin on the mechanism developing apoptosis in endometriotic foci, Choi et al. [32] reported that a progestin, dienogest, elevated autophagy through inhibiting mTOR pathway, but progesterone did not have such an effect.

Promoted apoptosis process has been increasingly studied in the treatment of malign neoplasia, as in the studies showing that inhibition of mTOR pathway using rapamycin analogs is efficient in the treatment of endometrial and ovarian cancers [33,34]. One of the mechanisms of uterine fibroids, the most common cause of benign gynecological tumoral lesions, is the telomerase activity and increased cell proliferation caused by mTOR pathway. The inhibition of the mTOR pathway by rapamycin was shown to decrease in smooth muscle cell proliferation in uterine fibroids [35]. In accordance with that study we observed that the inhibition of mTOR pathway decreased cell division.

The present study demonstrates the effect of everolimus on the inhibition of mTOR pathway as a possible treatment for endometriosis. However, it should be noted that the present study has several limitations. Firstly, side effects of everolimus treatment on normal endometrial tissue in the remaining uterine horn were not evaluated. Secondly, we did not investigate whether everolimus affected ovarian functioning through regular estrous cycle and/ or estrogen levels. And finally, we used only a standard everolimus dose and did not investigate the dose effects on endometriotic implant regression.

In the present preclinical study, everolimus was shown to lower the stage scores in the development of endometriosis, to decrease cell division and to increase apoptosis process. Anastrozole, a commonly used drug in the treatment of endometriosis, on the other hand, was shown to suppress endometriotic foci without affecting apoptosis efficiency. In accordance with the literature, we observed that anastrozole decreases ovarian reserve; however, inhibition of mTOR pathway through everolimus, a rapamycin analog, did not result in such a decrease; however, further studies to examine the nature of everolimus-induced ovarian reserve alteration need to be conducted.

\section{Conflict of Interest}

The author(s) declared no potential conflicts of interest with respect to the research, authorship, and/or publication of this article. The author(s) received no financial support for the research, authorship, and/or publication of this article.

\section{References}

[1] Johnson N, Farquhar C, Crossley S et al. A double-blind randomised controlled trial of laparoscopic uterine nerve ablation for women with chronic pelvic pain. BJOG 2004; 111: 950-959

[2] Adamson G, Kennedy S, Hummelshoj L. Creating solutions in endometriosis: global collaboration through the World Endometriosis Research Foundation. J Endometriosis 2010; 2: 3-6

[3] Simoens S, Dunselman G, Dirksen C et al. The burden of endometriosis: costs and quality of life of women with endometriosis and treated in referral centres. Hum Reprod 2012; 27: 1292-1299

[4] Platteeuw L, D'Hooghe T. Novel agents for the medical treatment of endometriosis. Curr Opin Obstet Gynecol 2014; 26: 243-252

[5] Braza-Boïls A, Marí-Alexandre J, Gilabert J et al. MicroRNA expression profile in endometriosis: its relation to angiogenesis and fibrinolytic factors. Hum Reprod 2014; 29: 978-988

[6] Johnson NP, Hummelshoj L, Abrao M et al. Consensus on current management of endometriosis. Hum Reprod 2013; 28: 1552-1568

[7] McLaren J. Vascular endothelial growth factor and endometriotic angiogenesis. Hum Reprod Update 2000; 6: 45-55

[8] Cinar O, Seval Y, Uz YH et al. Differential regulation of Akt phosphorylation in endometriosis. Reprod Biomed Online 2009; 19: 864-871

[9] Harada T, Kaponis A, Iwabe T et al. Apoptosis in human endometrium and endometriosis. Hum Reprod Update 2004; 10: 29-38

[10] Leconte M, Nicco C, Ngô C et al. The mTOR/AKT inhibitor temsirolimus prevents deep infiltrating endometriosis in mice. Am J Pathol 2011; 179: 880-889

[11] Ellard SL, Clemons M, Gelmon KA et al. Randomized phase II study comparing two schedules of everolimus in patients with recurrent/metastatic breast cancer: NCIC Clinical Trials Group IND.163. J Clin Oncol 2009; 27: $4536-4541$

[12] Vernon MW, Wilson E. Studies on the surgical induction of endometriosis in the rat. Fertil Steril 1985; 44: 684-694

[13] Keenan JA, Williams-Boyce PK, Massey PJ et al. Regression of endometrial explants in a rat model of endometriosis treated with the immune modulators loxoribine and levamisole. Fertil Steril 1999; 72: 135-141

[14] Donnez J, Smoes P, Gillerot $S$ et al. Vascular endothelial growth factor (VEGF) in endometriosis. Hum Reprod 1998; 13: 1686-1690

[15] Remmele W, Stegner H. Recommendation for uniform definition of an immunoreactive score (IRS) for immunohistochemical estrogen receptor detection (ER-ICA) in breast cancer tissue. Pathologe 1987; 8: 138

[16] Oral E, Demir B, Inceboz U. Endometriosis and ovarian reserve. Women's Health 2015; 11: 671-675

[17] Meresman GF, Bilotas M, Abello V et al. Effects of aromatase inhibitors on proliferation and apoptosis in eutopic endometrial cell cultures from patients with endometriosis. Fertil Steril 2005; 84: 459-463

[18] Amsterdam LL, Gentry W, Jobanputra S et al. Anastrazole and oral contraceptives: a novel treatment for endometriosis. Fertil Steril 2005; 84: 300-304

[19] Yildiz C, Kacan T, Akkar OB et al. Effect of imatinib on growth of experimental endometriosis in rats. Eur J Obstet Gynecol Reprod Biol 2016; 197: 159-163 
[20] Thangavelu A, Hewitt M], Quinton ND et al. Neoadjuvant treatment of endometrial cancer using anastrozole: a randomised pilot study. Gynecol Oncol 2013; 131: 613-618

[21] Streuli I, de Ziegler D, Santulli P et al. An update on the pharmacological management of endometriosis. Expert Opin Pharmacother 2013; 14 : 291-305

[22] Burgova EN, Tkachev NA, Paklina OV et al. The effect of dinitrosyl iron complexes with glutathione and S-nitrosoglutathione on the development of experimental endometriosis in rats: a comparative studies. Eur J Pharmacol 2014; 741: 37-44

[23] Matsui H, Asami T. Effects and therapeutic potentials of kisspeptin analogs: regulation of the hypothalamic-pituitary-gonadal axis. Neuroendocrinology 2014; 99: 49-60

[24] Gibran L, Maranhão RC, Abrão MS et al. Could statins constitute a novel treatment for endometriosis? Systematic review of the literature. Eur J Obstet Gynecol Reprod Biol 2014; 179: 153-158

[25] Wang Y, Lin M, Weng $\mathrm{H}$ et al. ENMD-1068, a protease-activated receptor 2 antagonist, inhibits the development of endometriosis in a mouse model. Am J Obstet Gynecol 2014; 210: 531.e531-531.e538

[26] Santanam N, Kavtaradze N, Murphy A et al. Antioxidant supplementation reduces endometriosis-related pelvic pain in humans. Transl Res 2013; 161: 189-195

[27] Leavy O. Reproductive immunology: evading immunosurveillance in endometriosis. Nat Rev Immunol 2015; 15: 729-729
[28] Baselga J, Campone M, Piccart M et al. Everolimus in postmenopausal hormone-receptor-positive advanced breast cancer. N Engl J Med 2012; 366: 520-529

[29] Franz DN, Belousova E, Sparagana S et al. Efficacy and safety of everolimus for subependymal giant cell astrocytomas associated with tuberous sclerosis complex (EXIST-1): a multicentre, randomised, placebo-controlled phase 3 trial. Lancet 2013; 381: 125-132

[30] Laschke M, Elitzsch A, Scheuer C et al. Rapamycin induces regression of endometriotic lesions by inhibiting neovascularization and cell proliferation. Br J Pharmacol 2006; 149: 137-144

[31] Yagyu T, Tsuji Y, Haruta S et al. Activation of mammalian target of rapamycin in postmenopausal ovarian endometriosis. Int J Gynecol Cancer 2006; 16: 1545-1551

[32] Choi J, Jo M, Lee E et al. Dienogest enhances autophagy induction in endometriotic cells by impairing activation of AKT, ERK1/2, and mTOR. Fertil Steril 2015; 104: 655.e1-664.e1

[33] Wagner S, Dancey JE. Potential future Indication of Rapamycin Analogs for the Treatment of solid Tumors. In: Mita M, Mita A, Rowinsky EK, eds. mTOR Inhibition for Cancer Therapy: Past, Present and Future. Paris: Springer; 2016: 229-249

[34] Meyer LA, Slomovitz BM, Djordjevic B et al. The search continues: looking for predictive biomarkers for response to mTOR inhibition in endometrial cancer. Int J Gynecol Cancer 2014; 24: 713

[35] Suo G, Sadarangani A, Tang $W$ et al. Telomerase expression abrogates rapamycin-induced irreversible growth arrest of uterine fibroid smooth muscle cells. Reprod Sci 2014; 21: 1161-1170 